\title{
A family study of bladder exstrophy
}

\author{
ELIZABETH IVES*, REBECCA COFFEY, AND C O CARTER
}

From MRC Clinical Genetics Unit, Institute of Child Health, London WC1N $1 E H$

SUMMARY The families of 102 index patients with bladder exstrophy treated at The Hospital for Sick Children, Great Ormond Street were studied in an attempt to arrive at an empirical risk of recurrence for sibs. Of the 102 patients, 89 had complete exstrophy, eight had partial exstrophy (variant), and five had exstrophy of the cloaca.

In all they had 162 sibs, none of whom had bladder exstrophy. The risk to sibs, in this study and from reports by surgeons of sib pairs in their consecutive series, is low and probably less than $1 \%$. There is a suggestion of an increase in central nervous system malformations in sibs as well as in the index patients.

Bladder exstrophy is a defect of the infraumbilical abdominal wall. The minimal degree of such a defect is epispadias alone and this is not included in this study. The relatively common intermediate degree of the defect is complete bladder exstrophy, with epispadias or bifid clitoris, anteriorly ectopic and often stenotic anus, and wide separation of the pubic symphysis. Frequently associated anomalies include duplication of the uterus and vagina. In a minority of cases only part of the bladder is exposed. This may be at either the upper or lower end, or a portion of exstrophic bladder may be separated from the remainder of the bladder which is covered. These forms are usually labelled 'variants' of bladder exstrophy. The rare and most severe degree is exstrophy of the cloaca, in which the lateral portion of the exposed mucosa represents the two halves of the posterior wall of the bladder, but the central portion is intestinal epithelium. The anus is imperforate. Above the exstrophy there is a broad exomphalos. The female genital tract is usually duplicated.

The basic defect is probably failure of fusion of the secondary mesoderm (from the primitive streak) in the midline of the anterior abdominal wall, with subsequent rupture of the thin wall consisting only of ectoderm and endoderm. Early rupture (5th week) results in exstrophy of the cloaca, later rupture (7th week) in exstrophy of the bladder. ${ }^{1}$

The earliest known report must surely be the description on an Assyrian tablet of about 2000 BC, now in the British Museum, London.

*Present address: Department of Paediatrics, University of Saskatchewan, Saskatoon, Canada.

Received for publication 6 June 1979.
The incidence of the condition is often quoted as 1 in 30000 to $40000 .^{2-4}$ Rickham $^{2}$ notes a discrepancy in figures from Liverpool, which were 1 in 40000 before 1953 and 1 in 10000 between 1954 and 1960; he considers the latter figure is probably more correct since the lower figure, more often quoted, is likely to include only those cases referred to surgeons.

However, more precisely, among total births ascertained in 1950 to 1959 in Birmingham, ${ }^{5}$ nine cases were found in 190236 births, an incidence of a little less than 1 in 20000 . The sex ratio is usually quoted as being between $2: 1^{36}$ and $3: 1 .^{7} 8$ The cause of the condition has remained obscure with no specific teratogen having been identified. Chromosomes were normal in 35 families studied in Minneapolis. ${ }^{4}$

In four sizeable studies, family history has been specifically mentioned. Chisholm ${ }^{4}$ reported two sib pairs affected in a series of 137 index patients (two brothers and a brother and sister pair). Williams and Savage ${ }^{8}$ reported two brothers affected among 80 cases at The Hospital for Sick Children, Great Ormond Street between 1949 and 1963 (both sibs were treated at this hospital, but neither came into the present series which includes only those attending after 1965). Lattimer and Smith ${ }^{7}$ had no affected sibs in a series of 138 cases. Higgins, ${ }^{3}$ in a series of 158 patients, stated "... the malformation rarely occurs in members of the same family. I have observed it in twins on only two occasions and twice in brother and sister". He does not specify that these familial cases belonged to his series of 158 patients. Uson et $a l^{9}$ reported a pair of male monozygotic twins, both with complete exstrophy, in a series of 66 cases.

In order to obtain an empirical recurrence risk 
for parents having already had one child with this severe and troublesome condition, a systematic family study was undertaken.

\section{Material and methods}

The index patients were 102 children ( 71 boys and 31 girls) with exstrophy of the bladder attending The Hospital for Sick Children, Great Ormond Street between 1966 and 1973. Complete bladder exstrophy was present in 89 (67 boys and 22 girls), partial bladder exstrophy in eight (one boy and seven girls), and exstrophy of the cloaca in five (three boys and two girls). Details of the three groups together with associated malformations present are shown in the table.

We set out to trace and, with the permission of the family doctors, to interview the parents of each index patient. It was not possible to include seven families because one family was not willing to participate, it was considered unwise to visit another family with special problems, and five families had gone overseas. Family data were collected during home visits for the remaining 95 ( 65 boys and 30 girls) index cases. The family pedigree taken included sibs, parents, grandparents, aunts, uncles, and cousins, as well as the history of the pregnancy of the index patient.

\section{Results}

The average birthweight of the 82 patients, where the information was available, was $3.2 \mathrm{~kg}$ and no different from that of all live births. Similarly, measurements obtained wherever possible on current height and weight gave no indication of any interference with growth in childhood. Two patients were mentally retarded but intelligence in the remainder was within the normal range. Only three

TABLE Bladder exstrophy: 102 index patients showing type of exstrophy and other anomalies also present

\begin{tabular}{|c|c|c|}
\hline \multicolumn{2}{|c|}{ Index patients } & Other anomalies \\
\hline \multicolumn{3}{|c|}{ Total bladder exstrophy } \\
\hline & & $\begin{array}{l}\text { Aortic stenosis, mental retardation, } \\
\text { idiopathic hypercalcaemia }\end{array}$ \\
\hline Boys & 67 & Dorsal kyphosis and scoliosis \\
\hline Girls & 22 & Sacrococcygeal tumour, benign mass \\
\hline Total & 89 & Mental retardation \\
\hline \multicolumn{3}{|c|}{ Incomplete bladder exstrophy (variant) } \\
\hline \multirow{5}{*}{\multicolumn{3}{|c|}{$\begin{array}{l}\text { Boys } 1 \\
\text { Girls } \quad 7 \\
\text { Total } 8 \\
\text { Exstrophy of the cloaca }\end{array}$}} \\
\hline & & \\
\hline & & \\
\hline & & \\
\hline & & \\
\hline & & Posterior posterolateral sacral meningocele \\
\hline Boys & 3 & Sacrococcygeal meningocele \\
\hline Girls & 2 & \\
\hline Total & 5 & \\
\hline
\end{tabular}

index patients were dead and two of these had $\underset{\mathbb{D}}{\overparen{D}}$ exstrophy of the cloaca.

There is no indication of any effect of maternal age, $\overrightarrow{\vec{c}}$ birth order, or season of birth. Questioning all the mothers of index patients about possible prenatal $\frac{\mathrm{C}}{\mathrm{O}}$ factors, maternal illness, febrile episodes, or medica- $\frac{\bar{D}}{\bar{D}}$ tions gave no indication of any contributory environmental factors.

The sex ratio is $2: 3$ and similar to that found in other series.

\section{TWINS}

There was one set of discordant twins, both boys, who were thought to be dizygotic: they are now separated and adopted.

SIBS

The index patients had, in all, 162 sibs (90 brothers $\vec{\omega}$ and 72 sisters), none of whom had bladder exstrophy 을 or associated abnormality. The patients with cloacal $\rightarrow$ exstrophy had ten brothers and three sisters, those $\rightarrow$ with the variants had seven brothers and five sisters, and those with complete exstrophy had $73 \overrightarrow{\overrightarrow{0}}$ brothers and 64 sisters. Parents reported that no $\%$ other children had evidence of a possible minor degree of the exstrophy malformation complex, other genital anomalies, or difficulties with urinary control other than two sibs with mild nocturnal enuresis.

\section{PARENTS}

No parents were consanguineous and none had $\stackrel{ }{3}$ bladder exstrophy. The mother of the twins had right duplex kidney and double ureters.

\section{COUSINS}

The index patients had 424 male and 395 female $\overline{7}$ cousins none of whom had bladder exstrophy.

Sibs with other malformations included one with $\delta$ anencephaly, one with spinal dysraphism, one with $₹$ congenital heart disease (VSD and ASD), and one $\circ$ with unilateral cleft lip and palate. A further $D$ pregnancy was terminated at 5 months because of anencephaly.

\section{Discussion}

The recurrence risk after bladder exstrophy is clearly low. In this systematic study, of 162 sibs none was affected. The reports by urological surgeons of consecutive series of patients quoted above also 吕 suggest that the proportion of sibs affected is low. $T$ These in sum include three sib pairs of 421 patients, but the total of the normal sibs is not stated. For $\overrightarrow{\mathbb{D}}$ genetic counselling, at present, a recurrence risk of $\frac{\mathrm{D}}{\mathrm{D}}$ about $1 \%$ would appear appropriate. 
It is well known that there is an association of bladder exstrophy and spina bifida. ${ }^{4}$ In this series, two of 102 index patients had sacrococcygeal meningoceles. Of the 162 sibs, one had anencephaly and one spinal dysraphism, and a further pregnancy was terminated because of anencephaly. However, large studies of neural tube malformations ${ }^{10-12}$ report no instances of bladder exstrophy among index patients or their sibs.

We would like to thank the surgeons of The Hospital for Sick Children and in particular Mr D I Williams for permitting us access to their patients and for helpful advice.

\section{References}

1 Gray SW, Skandalakis JE. Embryology for surgeons. London: WB Saunders, 1972;422-37.

2 Rickham PP. The incidence and treatment of ectopia vesicae. Proc $R$ Soc Med 1961 ;54:389-92.

3 Higgins CC. Exstrophy of the bladder: report of 158 cases. Am Surg 1962;28:99-102.

4 Chisholm TC, McParland FA. In: Ravitch MM, Welch
KJ, Benson CD, Aberdeen O, Randolph, JG, eds. Pediatric surgery. 3rd ed, vol 2. Chicago: Year Book Medical Publishers 1979:1239.

5 Leck I, Record RG, McKeown T, Edwards JH. The incidence of malformations in Birmingham, England, 1950-1959. Teratology $1968 ; 1: 263-80$.

- Gross RE. The surgery of infancy and childhood. Philadelphia: WB Saunders, 1953.

7 Lattimer JK, Smith MJV. Exstrophy closure. A follow up on 70 cases. J Urol 1966;95:356-9.

8 Williams DI, Savage J. Reconstruction of the exstrophied bladder. Br J Surg 1966;53:169-73.

yson AC, Lattimer JK, Melicow MM. Types of exstrophy of urinary bladder and concomitant malformations. A report based on 82 cases. Pediatrics 1959;23:927-33.

10 Carter CO, David PA, Laurence KM. A family study of major central nervous system malformations in South Wales. J Med Genet 1968;5:81-106.

11 Richards IDG, McIntosh HT, Sweenie S. A genetic study of anencephaly and spina bifida in Glasgow. Dev Med Child Neurol 1972;14:626-39.

12 Carter CO, Evans K. Spina bifida and anencephalus in Greater London. J Med Genet 1973;10:209-34.

Requests for reprints to Professor C O Carter, MRC Clinical Genetics Unit, Institute of Child Health, 30 Guilford Street, London WC1N 1EH. 